\title{
Walter Benjamin relampeja em Guimarães Rosa
}

\author{
Lívia de Sá Baião \\ Pontifícia Universidade Católica do Rio de Janeiro, Rio de Janeiro, Brasil \\ livia.baiao@gmail.com
}

\begin{abstract}
Resumo: o objetivo deste artigo é destacar afinidades entre Walter Benjamin e Guimarães Rosa além de avaliar como os conceitos e pensamentos de Benjamin passaram a ser incorporados à fortuna crítica sobre Grande sertão: veredas ao longo das últimas décadas. Para tal, foram analisados textos dos principais pensadores que se dedicaram à obra de Rosa, com atenção especial àqueles que se debruçaram concomitantemente à obra de Benjamin no Brasil. Conclui-se que o pensamento benjaminiano passa a relampejar de forma cada vez mais intensa a partir da década de 90, com destaque especial para os conceitos de narrador, romance e epopeia e para os ensaios com uma abordagem mais histórica, política e social.
\end{abstract}

Palavras-chave: Guimarães Rosa; Walter Benjamin; afinidades; fortuna crítica; narrador; epopeia; romance.

\section{I - Introdução}

João Guimarães Rosa leu Walter Benjamin mas Walter Benjamin não leu João Guimarães Rosa. Benjamin poderia ter ensinado literatura alemã na recém inaugurada USP (Universidade de São Paulo), nos anos 30 (LÖWY, 2005, p. 9). Rosa poderia ter salvado Benjamin concedendo-lhe um visto para o Brasil como o fez para tantos outros judeus enquanto cônsul-adjunto em Hamburgo. Mas não, Benjamin infelizmente não conseguiu cruzar a fronteira de Port-Bou antecipando, com uma dose letal de morfina, o fim de sua vida, e Rosa não cruzou o caminho de Benjamin, nem na vida, nem na literatura. Além de Rosa só ter publicado seu primeiro livro Sagarana, em 1946, seis anos após o suicídio de Benjamin, seria bastante improvável que este último se debruçasse sobre a obra de um autor brasileiro. Entretanto, se o fizesse, certamente Rosa brilharia na "“-constelação"'”- de escritores aos quais Benjamin dedicou-se ao longo de sua vida, com maior ou menor intensidade: Baudelaire, Goethe, Leskov, Proust, Kafka, Döblin, Brecht e tantos outros. Como seria o Rosa visto pelas lentes de Benjamin? Que título elegeria para um ensaio literário sobre Grande sertão: veredas: Imagem de Rosa, Sobre alguns temas em Rosa ou O narrador? Que aspectos de sua obra teria ressaltado?

Muito foi escrito sobre Rosa. Há uma imensa, brilhante e quase paralisante fortuna crítica que continua crescendo a cada ano. Muito foi escrito sobre Benjamin. 
Este quase indefinível crítico literário, escritor, marxista, judeu, filósofo "'-fora da tradição manifesta da filosofia"'", (ADORNO apud BENJAMIN; OSBORNE, 1997, p. 11) foi amplamente estudado, analisado e revisitado no Brasil a partir do final da década de 60 quando começaram a ser publicadas as primeiras traduções para o português. Entretanto, foi somente a partir da década de 90 que, de forma lenta e definitiva, os pensamentos e conceitos de Benjamin infiltraram-se nas análises e críticas literárias sobre a obra de Guimarães Rosa como se verá a seguir.

\section{II - Afinidades eletivas: Walter Benjamin e Guimarães Rosa}

Comecemos por indagar se faz realmente sentido aproximar dois autores tão distantes quanto Guimarães Rosa e Walter Benjamin. O que poderiam ter em comum um alemão, burguês, judeu e marxista que escreveu intensamente sobre cidades e outro brasileiro que, apesar de cosmopolita e poliglota, só escreveu sobre o sertão? São muitas as respostas mas as primeiras foram dadas pelo próprio Rosa na sua entrevista a Günter Lorenz: "“-Goethe nasceu no sertão, assim como Dostoievsky, Tolstoi, Flaubert, Balzac; ele era como os outros que eu admiro, um moralista, um homem que vivia com a língua e pensava no infinito. Era um sertanejo."'" (LORENZ, 1983, p. 85). E ainda:

[p]ortanto torno a repetir: não do ponto de vista filológico e sim do metafísico, no sertão fala-se a língua de Goethe, Dostoievsky e Flaubert, porque o sertão é o terreno da eternidade, da solidão, onde Inneres und Ausseres sind nicht mehr zu trennen ${ }^{1}$, segundo Westöstlicher Divan ${ }^{2}$ (ibidem, p. 86).

Nestas duas frases surgem importantes afinidades eletivas entre Benjamin e Rosa. Primeiro cabe sublinhar o lugar de destaque que Goethe ocupa na constelação de escritores admirados pelos dois autores. Enquanto Rosa explicita sua admiração na já mencionada entrevista, Benjamin dedica dois ensaios específicos ao escritor romântico alemão, o primeiro sobre o livro Afinidades eletivas e o segundo, um verbete escrito entre 1926 e 1928, encomendado pela Grande enciclopédia soviética. Pensamos ser possível incluir Benjamin ao lado de Goethe, Dostoievsky e Flaubert, nessa lista rosiana de homens que "“"pensam no infinito"'”, na eternidade e na solidão, terreno onde o interior e o exterior não podem ser separados porque todos falam esta mesma “"'língua"'”, são sertanejos.

Também língua e linguagem aparecem como questões fundamentais no pensamento de Benjamin e Rosa. Benjamin dedicou-se desde muito cedo a esses temas, tendo desenvolvido sua teoria sobre a linguagem a partir do ensaio "'Sobre as linguagens em geral e sobre a linguagem humana"'”, de 1916, aprofundando-a em "“'A tarefa do tradutor"'”, de 1923, na introdução a Origem do drama barroco alemão, publicado em 1924 e, finalmente, em "'-Problems in the sociology of language"'”- da segunda metade da década de 30 . Para Benjamin, tudo que existe no mundo, os objetos, animais, plantas e homens se expressam através de alguma forma linguagem e esta se afasta de qualquer função utilitária, comunicando apenas a essência das coisas. Em Benjamin, falam as estrelas, os astros, as borboletas e as 
flores. Em Rosa, falam os bois, falam os burros e as coisas. Os morros mandam recados. Para Benjamin, a língua de Adão no paraíso é o ponto de partida e, ao mesmo tempo, o ponto de chegada. Rosa diz: "“'Deus era a palavra e a palavra estava com Deus"'”. (LORENZ, 1983, p. 88). Rosa queria "“"voltar a cada dia à origem da língua, lá onde a palavra está nas entranhas da alma"'” (ibidem, p. 84), achava que “"'[o] idioma é a única porta para o infinito, mas infelizmente está oculto sob montanhas de cinzas. Daí resulta que tenha de limpá-lo..."'- (ibidem, p. 83), o mesmo que procura fazer o filósofo alemão escovando a língua e a história "“-a contrapelo"'-" e escavando o passado como quem escava uma cidade soterrada. (BENJAMIN, 2012b, p. 245).

Marilia Rothier Cardoso, em seu ensaio "'Cadernos de Rosa: uma lição benjaminiana sobre a arte da linguagem"'” já havia identificado "“"uma impressionante semelhança entre o pensamento dos dois escritores"'”:

\begin{abstract}
Benjamin formula o conceito da linguagem para além de qualquer intencionalidade comunicativa ou qualquer utilitarismo informacional: "a linguagem comunica é a essência linguística das coisas"'-' (Benjamin, 1971, p. 81). Em consequência, o conceito engloba e aproxima as línguas articuladas dos homens e a linguagem "'-muda"'” da natureza, operando um deslocamento vertiginoso da razão lógica para a revelação mística. Essa trajetória é, precisamente, o ponto de encontro da aventura filosófica do alemão com a viagem ficcional do brasileiro. Para interferir em circunstâncias político-culturais diversas, ambos escolhem estratégia equivalente - transportar o leitor para um tempo simultâneo onde os mitos modernos, propostos à maneira do oráculo arcaico, perdem sua credibilidade autoritária. Seja para Benjamin, seja para Guimarães Rosa, a tarefa da nomeação, atribuída aos homens, se os destaca dos demais seres é em função de um empréstimo de uma linguagem sagrada comum a todos e, portanto, tanto melhor empregada quanto mais experimentalmente próximo o nomeador esteja das coisas nomeadas. (CARDOSO, 2006, p. 113)
\end{abstract}

Da linguagem passamos à oralidade, já que a tradição oral também ocupa lugar central na obra dos dois autores. Benjamin dedica boa parte do ensaio "-"O narrador"'-' para louvar o grande contador de histórias, "“-_a experiência que passa de boca em boca"'” (BENJAMIN, 2012a, p. 214), a tradição oral da poesia épica, o dom de ouvir e as comunidades de ouvintes. Não por acaso, Rosa escolhe abrir Grande sertão: veredas com um travessão e "“"Desenredo"”,", oitava estória de Tutaméia, começa com "“"Do narrador a seus ouvintes: - Jó Joaquim, cliente, era quieto, ..."'” (ROSA, 1967, p. 38). Por isso talvez a prosa altamente poética, as onomatopeias, a primazia dos sons e o valor de cada palavra sejam seminais para ambos.

Pode-se dizer também que a questão do tempo perpassa cada fragmento de Benjamin e cada estória de Rosa. Os dois lutam contra o tempo inumano, abstrato e insaciável dos relógios e dos cronômetros (GAGNEBIN, 2004, p. 52), recusam-se a escrever de forma linear e a obedecer a ordem cronológica dos fatos. Mas não o fazem como os novos Josués que, irritados com a hora, "-_alvejam o relógio para suspender o dia"'-" (BENJAMIN, 2012c, p. 19). Rosa e Benjamin escolhem enfrentar 
a passagem inexorável do tempo através da narrativa, recorrendo à força da linguagem.

Infância berlinense: 1900 está longe de ser uma biografia cronologicamente ordenada que conta a infância de um menino burguês alemão em Berlim. Para narrar sua experiência enquanto criança, Benjamin escolhe escrever um conjunto de fragmentos seguindo "-"a irreversibilidade do tempo passado, não como qualquer coisa de causal e biográfico, mas sim de necessário e social."'-' (BENJAMIN, 2013, p. 69). O tempo "-"entrecruzado"'-' que antecede o conceito de "“iimagem dialética"'”' surge na leitura que Benjamin faz de Em busca do tempo perdido. Ao molhar a madeleine no chá, o passado comparece involuntariamente, como um lampejo, no "“"'agora"'" de Marcel, o personagem central do romance. É somente nesse instante que a imagem de Combray é integralmente recuperada. Se as narrativas não acontecem de forma linear em Paris e Berlim, tampouco é assim no sertão rosiano. Lá, onde também se fala a língua de Goethe, as estórias não se submetem aos ponteiros dos relógios. Riobaldo, herói de Grande sertão: veredas declara:

\footnotetext{
[c]ontar seguido, alinhavado, só mesmo sendo as coisas de rasa importância. De cada vivimento que eu real tive, de alegria forte ou pesar, cada vez daquela hoje vejo que eu era como se fosse diferente pessoa. Sucedido desgovernado. Assim eu acho, assim é que eu conto. (ROSA, 2006, p. 88, 89)
}

Associados à questão do tempo estão os conceitos benjaminianos de memória, rememoração, consciente, inconsciente, experiência (Erfahrung) e vivência (Erlebnis), muitos destes desenvolvidos nos ensaios de Benjamin enquanto crítico literário e que podem iluminar releituras de Grande sertão: veredas e outras obras de Rosa.

Há algumas afinidades um pouco mais prosaicas como o uso de cadernetas e o grande interesse por anagramas. Quanto às cadernetas de Benjamin, Hannah Arendt conta, no seu ensaio sobre o autor em Homens em tempos sombrios: "“-nada Ihe era mais característico nos anos 1930 do que os pequenos cadernos de notas, com capas pretas, que sempre levava consigo e onde incansavelmente introduzia, sob forma de citação, o que a leitura e a vida diária Ihe rendiam como 'pérolas' e 'coral'."'-' (ARENDT, 2013, p. 216). As famosas cadernetas de viagem de Rosa, muitas delas perdidas, infelizmente, foram matéria-prima e inspiração para seus livros. As mais conhecidas são aquelas batizadas pelo próprio Rosa de "“A boiada 1"'” e a "“"A boiada 2"'" quando passaram de cadernetas para textos datilografados e deram origem ao personagem Manuelzão além de revelar os caminhos trilhados pelos jagunços de Grande sertão: veredas. Já sobre anagramas, o mais famoso de Rosa é aquele contido em “"“Cara de Bronze"'”, “"“- Aí, Zé, ôpa!"”', que ele explica em sua carta ao tradutor italiano Edoardo Bizzarri, de 25 de novembro de 1963: "“intraduzível evidentemente: lido de trás para diante = apô éZ ía,: a Poesia"'”. De Benjamin, vale citar o título de seu artigo "“"Agesilaus Santander"-" que, como afirma seu amigo Gershom Scholem, seria um anagrama de Der Angelus Satanas.

Interessante também é a coincidência da metáfora do alquimista usada pelos dois autores. Benjamin compara o crítico ao alquimista que, ao olhar para a fogueira 
não se preocupa com as cinzas e a madeira, olha apenas para as chamas que preservam um enigma:

[s]e, por força de uma símile, quiser-se contemplar a obra em expansão como uma fogueira em chamas vívidas, pode-se dizer então que o comentador se encontra diante dela como o químico, e o crítico semelhantemente ao alquimista. Onde para aquele apenas madeira e a cinzas restam como objetos de sua análise, para este tão somente a própria chama preserva um enigma: o enigma daquilo que está vivo. Assim, o crítico levanta indagações quanto à verdade cuja chama viva continua a arder sobre as pesadas achas do que foi e sobre a leve cinza do vivenciado. (BENJAMIN, 2009, p. 13-14)

Já Rosa recorre à figura do alquimista para compará-la ao escritor. Diz ele:

[e]screver é um processo químico: o escritor deve ser um alquimista. Naturalmente, pode explodir no ar. A alquimia do escrever precisa de sangue do coração. Não estão certos quando me comparam a Joyce. Ele era um homem cerebral, não um alquimista. Para poder ser feiticeiro da palavra, para estudar a alquimia do sangue do coração humano, é preciso provir do sertão. (LORENZ, 1983, p. 85)

Estamos, com certeza, diante de dois alquimistas e poetas que têm a coragem de desafiar as convenções narrativas de maneira radical. Dois escritores e filósofos que pensam o mundo a partir de um olhar deslocado: Rosa/Riobaldo, um jagunço letrado que pensa o Brasil a partir do sertão; Benjamin, um alemão exilado que pensa a República de Weimar a partir de Paris do Segundo Império.

\section{III - Onde Benjamin e Rosa se cruzam}

Aparentemente, o filósofo e crítico literário Benedito Nunes foi o primeiro a fazer relampejar ideias e conceitos de Walter Benjamin sobre a obra de Rosa. Não nos seus ensaios sobre este autor contidos no famoso O dorso do tigre, de 1969, mas no artigo "“"Literatura e Filosofia"'" (NUNES, 2013, p. 140-168) publicado pela primeira vez em 1976 sob o título "'-A prática da interpretação de textos a partir de uma ótica interdisciplinar'"-' (II Encontro Nacional de Professores de Literatura) nos Cadernos da PUC-RJ ${ }^{3}$. Nesse texto, Nunes recorre a Benjamin ainda de forma tímida embora certeira, propondo aplicar a Grande sertão: veredas a reflexão de Benjamin sobre Afinidades eletivas de Goethe, que convoca a filosofia como guia, caracterizando-a como "“irmã'-" das obras artísticas e instância de questionamento: "-'desde o momento em que, ultrapassando as fundações, nos elevamos em nosso exame até a visão intuitiva do romance terminado, é a filosofia - e não o mito - que é chamada a nos servir de guia."'" (BENJAMIN apud NUNES, 2013, p. 164). Sete anos depois, Benjamin comparece novamente em "“.'A matéria vertente"'”, (NUNES, 2013, p. 169-195) onde a questão da temporalidade do romance é prob̄ematizada 
através do conceito benjaminiano de "“ideal do problema"'”, explicado em longa nota de rodapé que ocupa mais de quatro páginas do ensaio.

À exceção dos artigos de Benedito Nunes mencionados acima, é possível afirmar que, até a década de 80 , os textos clássicos da fortuna crítica de Rosa tais como O Homem dos avessos de Antonio Candido, A seta e o alvo de Oswaldino Marques, As formas do falso de Walnice Galvão e até mesmo Fórmula e fábula do bejaminiano Willi Bole não mencionavam Walter Benjamin ${ }^{5}$, tampouco a famosa coletânea de ensaios reunidos na Coleção fortuna crítica organizada por Eduardo Coutinho em 1983.

É somente a partir da década de 90 , quando proliferam as traduções para o português da obra de Benjamin e os fóruns de discussão como o Simpósio "“-Sete perguntas a Walter Benjamin"'-' em 1992, que suas ideias e conceitos começam a despontar, com maior frequência, nos textos acerca da obra de Guimarães Rosa. Em 1993, Kathrin Rosenfield cita Benjamin em duas oportunidades no livro Os descaminhos do Demo, no Prefácio e no último capítulo intitulado “"_A matriz formal do romance"'"'. No Prefácio, Rosenfield recorre a Benjamin para falar dos conceitos de memória e reminiscência e, ao final do livro, para aproximar as figuras de travessia e do símbolo do infinito que encerra o romance, à ideia kafkaniana de existência de uma "'"esperança infinita - somente não para nós"'"- descrita por Benjamin nos seus textos críticos e correspondências sobre Kafka (ROSENFIELD, 1993, p. 195).

Um ano depois, em 1994, Davi Arrigucci publica seu importante artigo "'-O mundo misturado"'”- sobre Grande sertão: veredas na Revista novos ensaios no qual destaca em Riobaldo características da figura modelar do narrador tradicional benjaminiano (BENJAMIN, 2012a, p. 213-241) e faz uma reflexão sobre a "'-mistura"'" das formas do romance e narrativa épica conforme a definição destes gêneros em "'-_O narrador"'-", concluindo:

\begin{abstract}
Com efeito, é sabido que a tradição oral, fonte da epopeia, nada tem a ver com o modo de ser próprio do romance, forma em ascensão a partir do início da Era Moderna que, pela primeira vez, entre as diferentes espécies de narrativa, como observou ainda Walter Benjamin, não provém da tradição oral nem a alimenta. No entanto, aqui é como se assistíssemos ao ressurgimento do romance de dentro da tradição épica ou de uma nebulosa poética primeira, indistinta matriz original da poesia, rumo à individuação da forma do romance de aprendizagem ou formação, com sua específica busca do sentido da experiência individual, própria da sociedade burguesa. (ARRIGUCCI, 1994, p. 20).
\end{abstract}

No mesmo ano, Willi Bolle, pensador alemão benjaminiano e rosiano, radicado no Brasil, publica "“"Grande sertão: cidade"'” na Revista USP, n. 24. Nesse artigo, Bolle "'toma emprestado"'-' instrumentos analíticos de Benjamin tais como

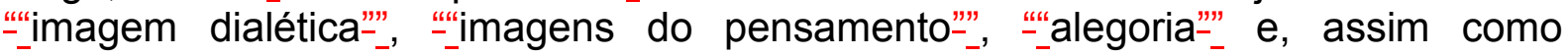
Árrigucci, adota as categorias de romance e narrativa épica do ensaio "'-_O narrador'”' para analisar Grande sertão: veredas como "“"romance urbano"'”, tentandō compreendê-lo como um retrato do Brasil no século XX (BOLLE, 94/95, p.82). Em 2000, volta ao tema e publica um artigo piloto “-'grandesertão.br ou: A invenção do 
Brasil'"'- que, 4 anos depois, será revisto e ampliado no livro grandesertao.br. Partindo do pressuposto de que Grande sertão: veredas é uma reescrita crítica de Os sertões de Euclides da Cunha e que as duas "-"obras são discursos de narradores-réus-e-testemunhas diante de um tribunal em que se julgam momentos decisivos da história brasileira"'", Bolle desenvolve a ideia de que o romance é, na verdade, uma releitura da história do Brasil e um estudo detalhado dos conflitos entre a classe dominante e as classes populares (2004, p. 8). Estende a Grande sertão: veredas a noção de "'"romance de formação"'”, no sentido de formação de um país e não de formação do indivíduo como Wilhelm Meister. Segundo o autor, o conceito de "'-romance de formação"'”- do Brasil se aplicaria porque Rosa teria resgatado a ideia de diálogo entre classes que Goethe defendeu no citado romance em lugar da revolução. Para fundamentar suas teses e pensamentos, Bolle interpreta Rosa usando toda sua bagagem de estudos sobre Benjamin.

De fato, aplicando a proposta metodológica de Benjamin, qual seja:
'Dissolver a mitologia no espaço da História', Bolle apresenta sua
interpretação do Grande Sertão: Veredas: deixando o sertão de ser assunto
temático, para ver nele uma 'forma de pensamento' até chegar na 'invenção
do Brasil'. Como o título sugere, 'grandesertão.br: A Invenção do Brasil'”',
Bolle apresenta sua versão e perspectiva de intepretação funcional e
histórica, em que os momentos decisivos do legado benjaminiano abrem,
para uma visão maior: 'www.grandesertao'ou 'grandesertao.com'.
(PRESSLER, 2006, p.338,339).

Segundo Jaime Ginzburg, no comentário à primeira edição do livro, Bolle dá grande importância à análise da categoria espaço, assim como ocorreu em seus estudos sobre Walter Benjamin. "“"A abordagem, além de investigar a especificidade semântica do vocábulo sertão, que desafia tradutores, inclui a exposição e o comentário de mapas. O leitor verificará o empenho de Bolle em unir Rosa e Benjamin em um 'redemunho'."'"-

A partir dos ensaios de 1994 de Arrigucci e Bolle, sucedem-se vários outros que aproximam conceitos e entrecruzam as ideias de Benjamin e Rosa. Em 1998, Susana Lages, em um texto intitulado "“'As asas da interpretação: notas sobre anjos em Walter Benjamin e Guimarães Rosa"'”- publicado nas trilhas de "'"O mundo misturado"'"- (também na Revista USP), faz uma análise da figura dos anjos em Benjamin e Rosa, com foco nos anjos de "“Evanira"'”, texto poético que integra o livro póstumo de Rosa, Ave palavra. Em outro ensaio, "-"Conversas com o tempo: Grande sertão: veredas"'”- do livro João Guimarães Rōa e a saudade, a distinção benjaminiana entre narrativa e romance é retomada por Susana Lages.

Também em 1998, mesmo ano de publicação de "“"As asas da interpretação"'”, Heloisa Starling defende sua tese de doutoramento publicada no ano seguinte sob o título Lembranças do Brasil - Teoria política, história e ficção em Grande sertão: veredas. Analisando Grande sertão: veredas sob uma perspectiva mais política e histórica, Heloisa pensa as questões da memória, história, modernidade e temporalidade a partir de conceitos benjaminianos. Rosa e Benjamin ali se encontram e caminham juntos através de uma "“estrada de muitos cotovelos"'". 
Alguns anos mais tarde, o italiano Ettore Finazzi-Agró, no Capítulo 2 de Um lugar do tamanho do mundo, publicado em 2001, refere-se a Grande sertão: veredas como texto de passagem, “-_ou Passagen-Werk no seu significado mais amplo de operação que põe em relação - lugar de trânsito que, em si mesmo, não deveria abrigar respostas, não deveria admitir, em princípio, a estabilidade da certeza, mas que dá acesso, afinal, a uma forma de verdade."'” (FINAZZI-AGRÓ, 2001, p. 53). Na nota que acompanha o termo Passagen-Werk, Finazzi-Agró esclarece que utiliza-o exatamente para assinalar seu parentesco com o trabalho de Walter Benjamin, voltando a esta questão em outros momentos no livro.

Cabe fazer um último destaque para o livro Memória e esquecimento no Grande sertão: veredas - Travessia e melancolia de Patricia Carmello, de 2013. Segundo a própria autora, o objetivo do ensaio foi

\begin{abstract}
seguir a rememoração, através da fala do narrador Riobaldo, a fim de pensar como são elaboradas no texto as noções de memória e esquecimento; buscando através de diferentes concepções da filosofia, da psicanálise e da teoria da arte, instrumentos de análise desta questão na obra. (CARMELLO, 2013, p. 11)
\end{abstract}

Nesta travessia, Carmello elege como "'-chaves"'”- para abrir as portas de leitura, conceitos de Benjamin, Freud e Maurice Halbwachs. De Benjamin, ela toma emprestado a concepção de narrativa épica e romance, memória, rememoração e história.

Pode-se dizer, então, que somente a partir dos anos 90 Benjamin foi essencial e definitivamente incorporado ao arcabouço teórico ao qual recorreram com grande frequência os críticos da obra de Rosa. Para uma melhor avaliação sobre os efeitos desta incorporação aos estudos sobre Grande sertão: veredas, vale evocar o agrupamento da fortuna crítica desta obra proposta por Bolle em grandesertão.br (2004, p. 19, 20):

1. Os estudos linguísticos e estilísticos como os de Mary L. Daniel;

2. As análises de estrutura, composição e gênero como as de Roberto Schwarz, Eduardo Coutinho, Benedito Nunes e Davi Arrigucci Jr. , que tecem relações intertextuais;

3. A crítica genética, como as contribuições de Maria Célia Leonel e Ana Luiza Martins da Costa, dedicadas a esclarecer o processo de elaboração da obra;

4. As interpretações esotéricas, mitológicas e metafísicas (Heloisa Vilhena de Araújo e Francis Utéza);

5. As interpretações sociológicas, históricas e políticas inauguradas por Walnice Galvão com As formas do falso que permaneceu isolado durante muito tempo e tiveram seu interesse renovado a partir do final da década de $90 \mathrm{com}$ os trabalhos de Heloisa Starling e Willi Bolle.

É possível notar que a obra de Benjamin foi essencial para fundamentar as interpretações de Grande sertão: veredas com viés mais político, sociológico e histórico que começaram a surgir, com maior intensidade, a partir de meados dos 
anos 90. O arcabouço teórico que já havia servido para refletir sobre as questões político-ideológicas no Brasil na década de 70 no contexto da ditadura militar e dos movimentos estudantis, passa a ser adotado também para trazer à tona os aspectos mais históricos e políticos do romance, 20 anos depois.

Os conceitos de memória, rememoração, romance, epopeia e a faculdade de narrar, dentre outros tantos, foram amplamente utilizados também nas renovadas e infinitas leituras desta grande "'-obra aberta"'- (ECO, 1976, p. 24,25) que, não por acaso, "“inacaba"'” com a banda de Moebius, uma história que nunca se fecha. Mas o que acontece quando a história não se fecha?

A multidão que assiste fica doente, contaminada por uma enfermidade que se chama a doença de sonhar. João Guimarães Rosa é um contador que não fechou a história. Ficamos doentes, nós que o escutamos. E amamos essa doença, esse encantamento, essa aptidão para a fantasia. Porque a todos não nos basta ter um sonho. Queremos mais, queremos ser um sonho. (COUTO, 2008, p. 72)

O desafio agora é pensar Walter Benjamin a partir de Guimarães Rosa. Seria possível pensar Benjamin como precursor de Rosa no sentido que Borges usa no seu famoso texto "“'Kafka e seus precursores"'”?

No vocabulário crítico, a palavra precursor é indispensável, mas se deveria tentar purificá-la de toda conotação de polêmica ou de rivalidade. O fato é que cada escritor cria seus precursores. Seu trabalho modifica nossa concepção do passado, como há de modificar o futuro. Nessa correlação, não importa a identidade ou a pluralidade dos homens. (BORGES, 2000)

Poderia a leitura de Rosa afinar e desviar sensivelmente a nossa leitura de Benjamin? Um interessante e promissor caminho a ser explorado.

Abstract: the objective of this article is to point out affinities between Walter Benjamin and Guimarães Rosa in addition to analyzing how Benjamin's concepts and thoughts were incorporated into the critical essays written on The devil to pay in the backlands in the past decades. To that end, we reviewed the works of the main critics specialized on the works of Rosa, particularly on those who focused on both, Rosa and Benjamin in Brazil. The conclusion is that Benjamin's thoughts and ideas start to flash more intensely from the nineties on, with a special emphasis on the concepts of narrator, novel and epic narratives and also on the essays with a more social, historical, and political approach.

Keywords: Guimarães Rosa; Walter Benjamin; afinidades; secondary literature; narrator; novel.

\section{Referências bibliográficas}


ARENDT, H. Homens em tempos sombrios. São Paulo: Companhia das Letras, 2008.

ARRIGUCCI, Davi. O mundo misturado, In: Revista novos estudos CEBRAP. São Paulo, n. 40, novembro 1994, p. 7-29.

BENJAMIN, A.; OSBURNE, P. A filosofia de Walter Benjamin: destruição e experiência. Rio de Janeiro: Jorge Zahar Ed., 1997.

BENJAMIN, W. A origem do drama barroco alemão. Belo Horizonte: Editora Autêntica, 2011.

. "“'Afinidades eletivas"'” In: Ensaios reunidos: escritos sobre Goethe.

São Paulo: Duas Ćidades, Editora 34, 2009.

Iluminuras, 1999.

O conceito de crítica de arte no romantismo alemão. São Paulo:

BENJAMIN, W. Obras Escolhidas I e II. São Paulo: Brasiliense, 2012a e 2012b.

- Obras Escolhidas III, Charles Baudelaire, um lírico na auge do capitalismo. São Paulo: Brasiliense, 1989.

. O anjo da história. Belo Horizonte: Autentica, 2012c.

. Passagens. Belo Horizonte: Editora UFMG, 2006.

. Rua de mão única, Infância berlinense: 1900. Belo Horizonte:

Editora Autentica, 2013.

Selected writings, Volume 2, 1927-1934. Cambridge, Massachusetts, and London, England: The Belknap Press of Harvard University Press, 1999.

BOCK, W. Benjamin's criticism of language and literature. In: A companion to the works of Benjamin, p. 23-45. New York: Camden House, 2009.

BOLLE, W. Fisiognomia da metrópole moderna: Representação da história em Walter Benjamin. São Paulo: Editora da Universidade de São Paulo, 2000.

. Fórmula e fábula. São Paulo, Editora Perspectiva, 1973.

1994/5, p. 80-93.

Grande sertão: cidades, Revista USP, São Paulo: n. 24, dez/fev . grandesertão.br. São Paulo: Editora 34, 2004. 
BORGES, J. L. Kafka e seus precursores. In: Obras completas, vol. II. São Paulo: Globo, 2000.

CARDOSO, M. R. Cadernos de Rosa: uma lição benjaminiana sobre a arte da linguagem, Rio de Janeiro: Revista de letras, n. 28, Vol 1/2, jan/dez 2006, p. 112115.

CARMELLO, P. Memória e esquecimento no Grande sertão: veredas - Travessia e melancolia. Rio de Janeiro: 7 Letras, 2013.

COUTO, M. Encontros e encantos, Rosa em Moçambique, In.: STARLING, H. M.; ALMEIDA, S. (orgs.) Sentimentos do Mundo - Ciclo de conferências dos 80 anos da UFMG, Belo Horizonte: Editora UFMG, 2009, p. 63-72.

ECO, U. Obra aberta. São Paulo: Perspectiva, 1976.

FINAZZI-AGRÓ, E. Um lugar do tamanho do mundo. Belo Horizonte: Ed. UFMG, 2001.

GAGNEBIN, J. M. História e narração em Walter Benjamin. São Paulo: Perspectiva, 2004.

LAGES, S. K. João Guimarães Rosa e a saudade. São Paulo: Ateliê Editorial, FAPESP, 2002. . Tradução e melancolia. São Paulo: Edusp, 2007.

LORENZ, G. Diálogo com Guimarães Rosa. In: Eduardo COUTINHO (org). Guimarães Rosa: fortuna crítica. COUTINHO, Eduardo (org.). Rio de Janeiro: Civilização Brasileira, 1983, p.62-97.

LÖWY, M. Walter Benjamin: aviso de incêndio: uma leitura das teses “-Sobre o conceito de história'”'”. São Paulo: Boitempo, 2005.

NUNES, B. A Rosa o que é de Rosa: literatura e filosofia em Guimarães Rosa. Rio de Janeiro: DIFEL, 2013.

. O Dorso do Tigre. São Paulo: Editora 34, 2009.

PRESSLER, G. K. Benjamin, Brasil: A recepção de Walter Benjamin, de 1960 a 2005. São Paulo: Annablume editora, 2006.

ROSA, J. G. Correspondência com seu tradutor alemão Curt Meyer-Clason. Rio de Janeiro: Nova Fronteira/Editora da UFMG, 2003.

- Correspondência com seu tradutor italiano Edoardo

Bizzarri. São Paulo: Instituto Cultural Ítalo-Brasileiro, 2003a. 
2006.

Grande Sertão: Veredas. Rio de Janeiro, Nova Fronteira, Tutaméia. Rio de Janeiro: José Olympio Editoria. 1967.

ROSENFIELD, K. H. Os Descaminhos do Demo - Tradição e ruptura em Grande sertão: veredas. Rio de Janeiro: Imago Editora Ltda, 1993.

. Desenveredando Rosa. A obra de J.G. Rosa e outros rosianos. Rio de Janeiro: Topbooks, 2006.

STARLING, Heloisa. Lembranças do Brasil: teoria, política, história e fiç̧ão em Grande sertão: veredas. Rio de Janeiro: Revan: UCAM, IUPERJ, 1999.

\section{Notas}

\footnotetext{
1 "O interior e o exterior já não podem ser separados", tradução do próprio Eduardo Coutinho, organizador da Coleção.

2 Divã Ocidental.

3 In: Cadernos da PUC-RJ, Serie Letras e Artes, n. 28. Rio de Janeiro: Pontifícia Universidade Católica do Rio de Janeiro, 1976, p.7-24).

4 Publicado pelo primeira vez em 1983 (Seminário de Ficção Mineira II, Conselho Estadual de Cultura de Minas Gerais, Belo Horizonte, 1983, p. 9-28)

5 Na verdade Willi Bolle cita Walter Benjamin uma única vez no Capítulo 1 do livro Fórmula e Fábula, quando fala sobre a importância de se examinar as condições de transmissão, edição e difusão da obra para fazer uma crítica adequada da obra. Mas afirma que apesar da importância de uma análise da recepção nestes termos, não será este o seu objetivo central no livro, mas sim uma análise estruturais dos contos de Tutaméia. (BOLLE, 1973, p. 13)
}

Recebido em 24/07/2015

Aprovado em 04/09/2015

elSSN: $2179-8478$ 